\title{
ISRAEL COMPLEMENTARY INTERNATIONAL AIRPORT
}

\author{
Yair Wiseman \\ Computer Science Department \\ Bar-Ilan University, Ramat-Gan 52900, Israel \\ wiseman@cs.biu.ac.il
}

\begin{abstract}
Israel has just one major international airport named Ben-Gurion International Airport. Ben-Gurion Airport is overloaded and currently the Air Traffic Control in the airport is a very tough and complicated task. In addition BenGurion airport operates 24 hours a day for landings and in some days also 24 hours for takeoffs, which causes intolerable noise level. This paper explores the current state of affairs in Ben-Gurion Airport and suggests a possible complementary International Airport in Dothan Valley.
\end{abstract}

Keywords - Airport Site, Decibel Level, Airplane Noise, Landing Approach

\section{INTRODUCTION}

There are 17,678 commercial passenger airports over the world, not including military and other airports serving other purposes like transport of cargo, etc. [1].The International Air Transport Association (IATA) classifies them by three categories in terms of availability for landing and takeoff [2]. Almost all the airports are classifies at the highest category, whereas 139 at category 2 and another 170 airports (i.e. less than $1 \%$ ) are least available and classified at category 3. Israel main international airport - Ben-Gurion Airport is classified at category 3 .

The Ben Gurion Airport Terminal Control Area (TMA) covers a 22 miles strip that goes across the State of Israel from east to west, from the Jordanian border in the east to a distance of about 11.5 miles west of the Mediterranean coast. The southern border of this strip goes from Palmachim in the west to Kalia on the shores of the Dead Sea in the east; whereas the northern border goes from Gaash in the west to Pazzael in the east. This TMA strip is divided into two sections - Approach Control (APP) and Terminal Control.

Approach Control supervises aircrafts approaching Ben-Gurion airport from any direction, except of the north and the east, as well as aircrafts departing in these directions. Aircrafts arriving at Ben-Gurion airport from the north or east are supervised by the Terminal Control in coordination with Approach Control. Terminal Control supervises all the other aircrafts which are in the Terminal Control Area but not approaching Ben-Gurion airport.

Terminal Control and Approach Control are in charge of aircrafts flying at heights ranging from 1,300 to 5,000 feet, up to altitudes ranging from 8,000 to 10,000 feet, depending on the various regions.

The Air Traffic Control task in airports of category 3 is a very tough task and the air traffic control in Ben-Gurion airport is no exception; therefore, several 
suggestions for a complementary international airport have been put forward in order to take pressure off the air traffic in Ben-Gurion Airport.

Sede Dov Airport was closed at July 1, 2019 and its traffic has been moved to Ben-Gurion airport. This additional traffic has added another $4 \%$ to the number of flights in Ben-Gurion Airport and this is the straw that has broken the camel's back. Actually, the camel's back was already broken before the additional traffic of Sede Dov airport has been joined because Ben-Gurion is already beyond its capacity and many flights are delayed.

Since the 2000s, suggestions where to locate a complementary international airport have been put forward. The most prominent suggestions were:

1) Nevatim in the south of Israel.

2) Ramat David in Jezreel Valley.

3) An artificial island in the Mediterranean Sea.

Israel Air Force raises objections against Nevatim because there is already a large military airport in Nevatim and Israel Air Force wants complete control over the airport and its surroundings: air space and ground area.

Ramat David has been opposed by the residents of the Jezreel Valley who are anxious and troubled about the potential noise of an international airport.

An airport on an artificial island in the sea has been opposed by the Ministry of Finance because of the gigantic cost of such a project.

All Israel governments decided not to decide and turn the problem over to the next government.

In this paper we suggest a region about 10 miles to the south of Ramat-David. The site is called Dothan Valley and it is located between Mevo Dothan and Kabatya. Dothan Valley is advantageous because topographically, Dothan Valley is a flat area and additionally the landing and takeoff routes can be easily positioned in south of the Carmel ranges.

\section{CHOOSING A SITE FOR A COMPLEMENTARY INTERNATIONAL AIRPORT}

In recent years there has been an increase in the number of flights because of the population growth, the open sky agreement with the European Union (EU) [3] and the subsidy that Israel Ministry of Tourism has begun to offer to foreign airlines of about $€ 45$ per passenger [4]. A side effect of these government decisions was that a large number of tourists to Jordan decided to arrive by air to Israel and to continue by bus or other ground transportation to Jordan.

Figure 1 shows the number of passengers in Ben-Gurion Airport in recent years. From 2012 to 2018 , there was a boost of $80 \%$, which made Ben-Gurion airport very busy and incapable of handling the new mass of passengers. 


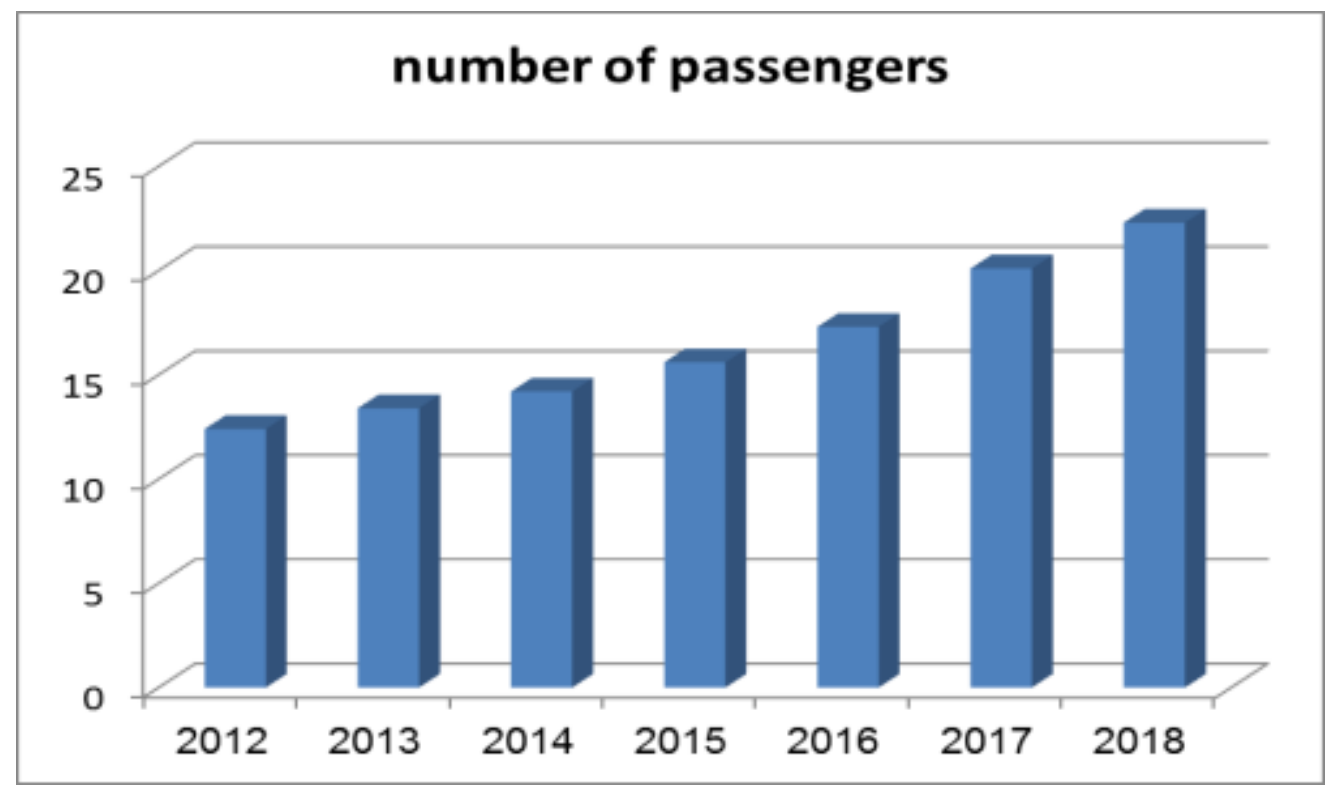

Fig. 1 Number of passengers (in millions) in Israel in recent years

The Shafran Report of November 2017 examined 21 proposals for alternative airports [5]; however, some proposals have been omitted for various reasons. Their conclusion was again to locate the complementary international airport in Nevatim or Ramat-David, although they know the longstanding resistance.

One and all agree that a complementary international airport is essential, necessary and even crucial for Israel; however, the airport location is controversial and contentious.

\section{DOTHAN VALLEY}

Dothan Valley is a valley in the north-west of Samaria about 10 miles southward from the city of Afula. Actually, Dothan Valley is the largest valley in the Samaria region. The valley is about 6 mile from west to east and 2 miles from north to south. The valley is surrounded by low hills. The distance between Dothan Valley and Jezreel Valley is very small - only about 3 miles.

Figure 2 is a picture of Dothan Valley and figure 3 is a map of Dothan Valley and its surroundings

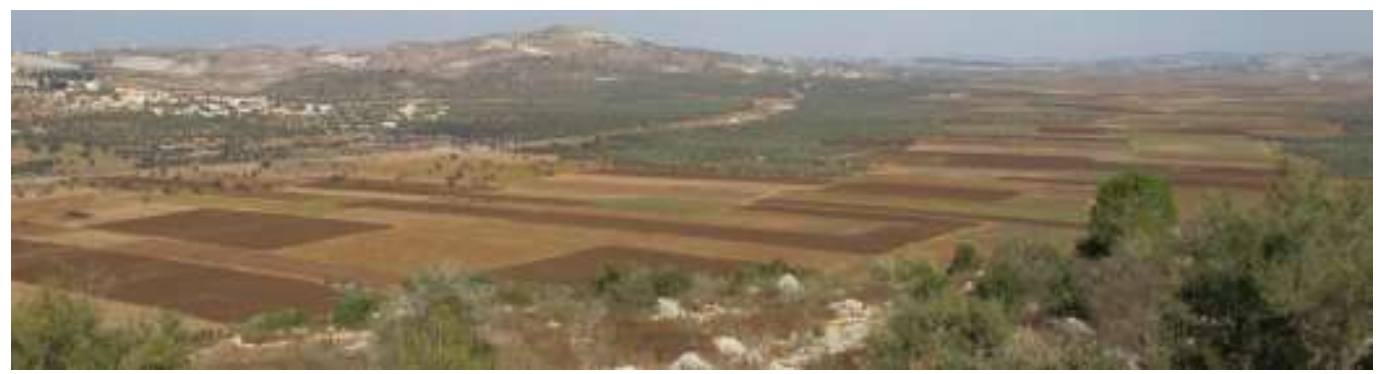

Fig. 2 Dothan Valley 


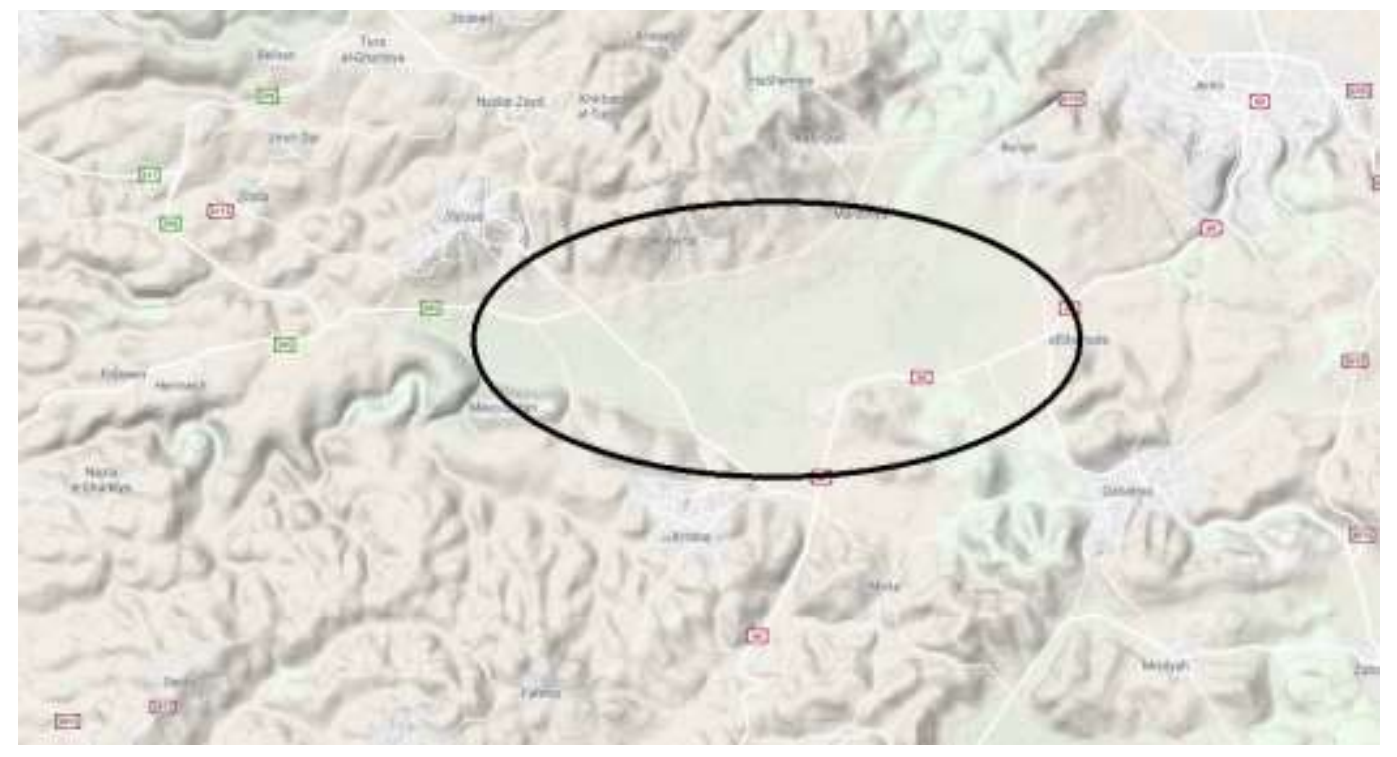

Fig. 3 Topography of Dothan Valley

Currently, Dothan Valley is mainly used for agriculture fields. The valley is mostly uninhabited with houses. In the center of Dothan valley there are ruins of the ancient settlement of Tel Dothan. The route of the Jenin-Nablus road (road no. 60) also runs through Dothan valley.

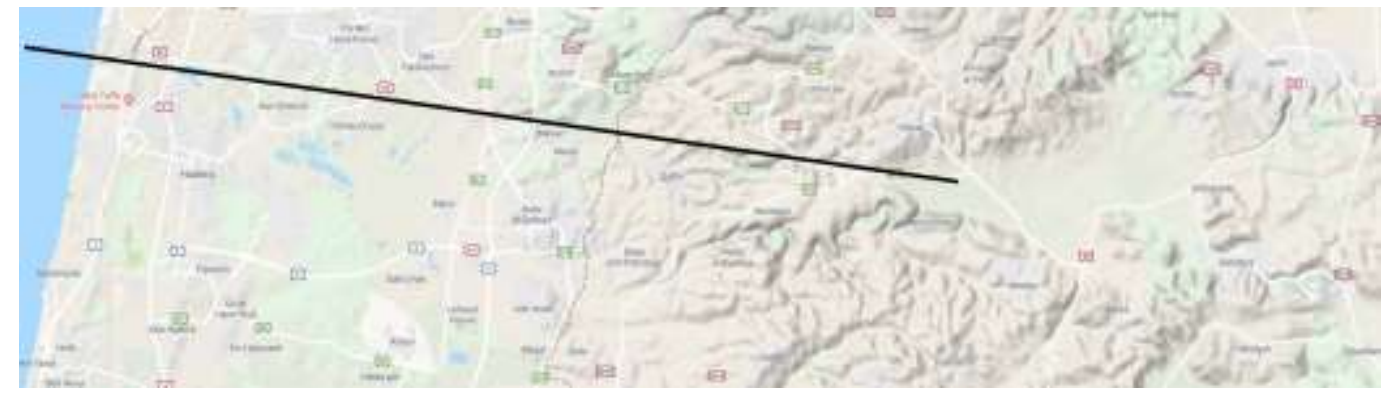

Fig. 4 Direction from 10/28 runway of possible Dothan Valley Airport

The airports in Jezreel Valley take into consideration the Carmel ranges; however, Dothan Valley is southwardly; therefore, even a runway with an angel to the north can be possible.

Airports runways are indicated by two numbers. These two numbers are the angles of the runways divided by ten [6]. There are two indication angles because airplanes can land or takeoff from both sides of the runway. For that reason, the two angles are always $\alpha$ and $\alpha+180$; however, these angles are always divided by ten, therefore the difference between the angels is constantly 18 .

In reality, examining the map of the municipalities and hills westward of Dothan Valley can disclose that best angel for the runway is 10/28. Most of the flights in Israel are westbound, so it is commonsensical to let this direction to set the angels of the runways. This flying route is shown in Figure 4.

\section{NOISE ABATEMENT ISSUES}

Decibel $(\mathrm{dB})$ stands for the ratio between two physical quantity values and is actually a logarithmic unit [7]. Specifically, one Bel is the ratio between two power 
quantities of 10:1, whereas one Decibel $(\mathrm{dB})$ is one tenth of the Bel (B) or in other words:

$$
1 B=10 \mathrm{~d} B .
$$

Decibels are commonly used for measurement of noise levels. Noises are actually a dynamic pressure of the air [8]. As a matter of fact, Decibels specify this pressure weigh against the absolute threshold of hearing (ATH). This pressure is commonly called Sound Pressure Level (SPL). Noise evaluated compared to absolute threshold of hearing (ATH) will be quantified by dBSPL; however the noise level is conventionally denoted by only "dB" [9]. The relation between dynamic pressure of the air and the noise in $\mathrm{dB}$ is calculated by this equation:

$$
D=\log _{10}\left(p^{20} / A T H^{20}\right) d B S P L
$$

Where

$\mathrm{D}$ is the noise measured in $\mathrm{dB}$.

$\mathrm{p}$ is the dynamic pressure of the air in Micro-Pascal.

An exact threshold of noise level considered as intolerable is different from one person to another and it is impossible to agree on; however $70-80 \mathrm{~dB}$ are generally considered as intolerable noise levels at day time, whereas $60-70 \mathrm{~dB}$ are considered as intolerable noise levels at night time [10].

Some researchers have pointed out that exceedingly loud noises can harm the physical and the mental health of the hearer [11].

In spite of this, Israel Airports Authority has been carrying out monitoring of take-off aircrafts. However, their standard is very lenient and tolerant for noise nuisance. The threshold for noise to be considered intolerable is $88-93 \mathrm{~dB}$ for heavy and long-range aircrafts and 85-91 dB for all other aircraft [12].

\section{BEN-GURION INTERNATIONAL AIRPORT}

There are three runways in Ben Gurion International Airport - 8/26, 12/30, $3 / 21$ [13]. That is to say a runway of 80 degrees or 260 degrees, a runway of 120 degrees or 300 degrees and a runway of 30 degrees or 210 degrees. Before an airplane lands, the airplane should position itself at the angle of the runway and against the wind if the wind is somewhat blowing hard.

In view of that, an airplane aims to land at runway $8 / 26$, will over Holon. Similarly, an airplane aims to land at runway 12/30, will over the south of Tel-Aviv and an airplane aims to land at runway $3 / 21$, will pass over Rosh-Haayin. Figure 5 shows an air photograph of Ben-Gurion Airport region including the runways and the municipals affected by these runways.

It can be noted that as can be clearly seen in Figure 5, if runway 12/30 was paved as $11 / 29$, the flights would pass over less populated areas; however, for historical reasons the runway was paved as $12 / 30$ and the flights pass over very populated areas. The flights cause extensive noise and moreover it is by some means less safe to fly over populated areas [14]. 


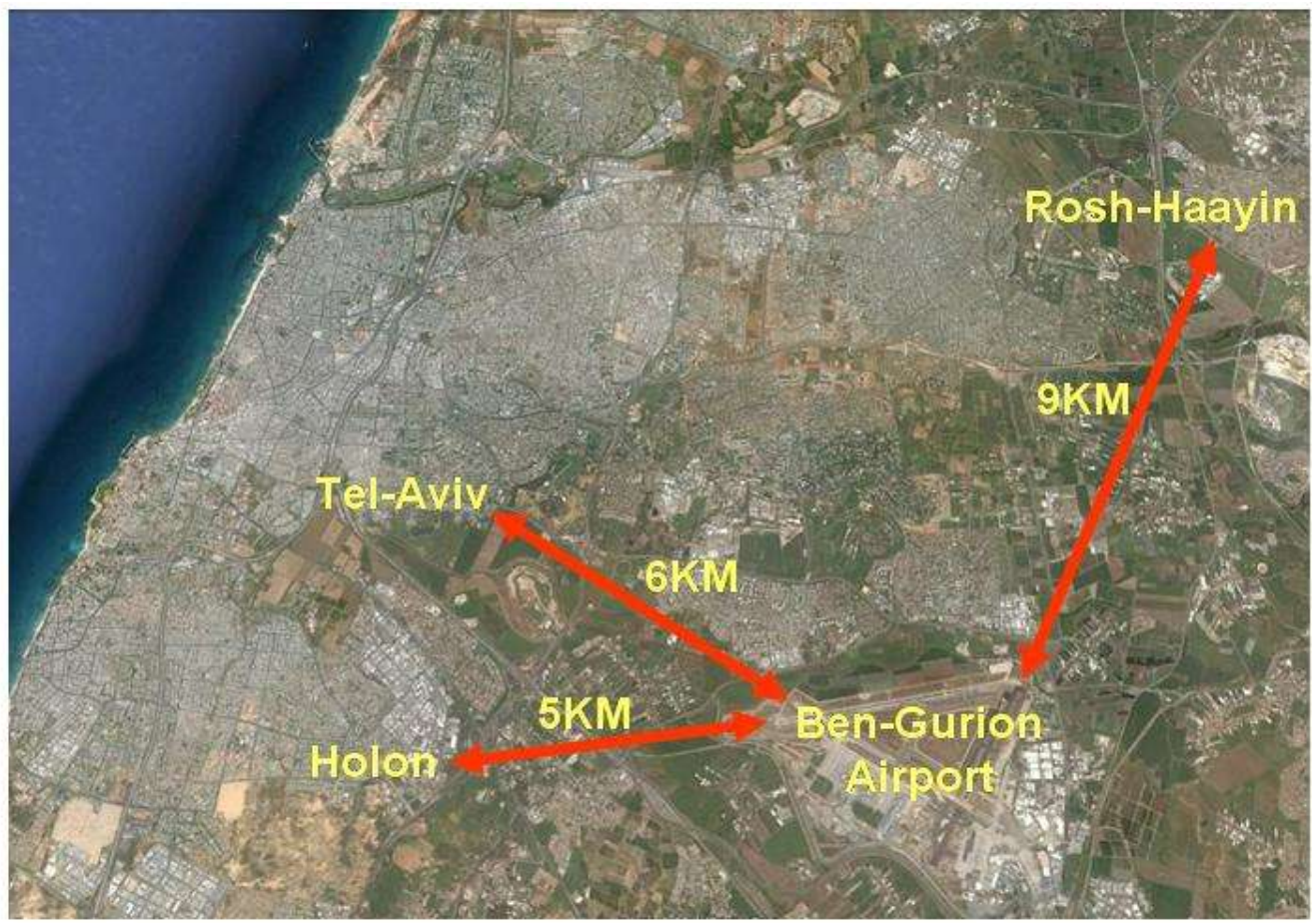

Fig. 5 Air photograph of Ben-Gurion International Airport

Because of the populate areas vicinity, takeoffs between 1:40 AM and 5:50 AM are prohibited in Ben-Gurion Airport, but not during the night between Thursday and Friday and on nights falling before holiday eves. There is no time limit on landings and they are carried out even in the small hours of the night.

The west of Dottan Valley is sparsely populated; therefore, a possible international airport in Dothan Valley can be operated during any time with a noise nuisance to only small number of people. Even near the shore line of the Mediterranean Sea which is the most populated area in Israel, the flying route can be between Hadera and Pardes Chana and not above these cities.

\section{ALTITUDE AND NOISE NUISANCE}

The actual altitude is commonly measured by an altimeter [15] and periodically recorded in the flight data recorder [16]; yet, the airplane altitude can be assessed using to this equation:

$A l t=S F+d * \operatorname{tg}(\alpha)$

Where:

Alt is the airplane altitude.

$\mathrm{d}$ is the distance of the airplane from the edge of the runway.

$\alpha$ is the landing approach angle.

SF is a Safety Factor, ensuring the airplane will not land ahead of the runway.

SF is usually around 0.01 miles (about $16 \mathrm{M}$ ). The standard landing approach angle is typically about $3^{\circ}$ [17]. Taking this numbers and using the equation above, the altitudes of the airplanes above the cities in the vicinity of Ben-Gurion Airport will be as shown in Fig. 6 . 
The locations that will be mostly affected by a possible airport in Dothan Valley are a kibbutz named Metzar populated by 377 residents - 13KM from the runway, the psychiatric medical campus named Shaar Menashe $-18 \mathrm{KM}$ and the kibbutz Gan Shmuel populated by 905 residents $-22 \mathrm{KM}$. Taking this distances and using the equation above, the altitudes of the airplanes above the cities in the vicinity of possible Dothan Valley Airport will be as shown in Fig. 7.

The noise of an airplane is affected by its distance, the wind and the temperature [18]; however, the most dominant parameter is the distance [19]. Wind blowing from the airplane side will amplify the noise; whereas wind blowing toward the airplane will reduce the noise. Also, as the temperature gets higher, the noise will be amplified. It should be also noted that fog, clouds, and rain have no substantial effect on the noise level [20].

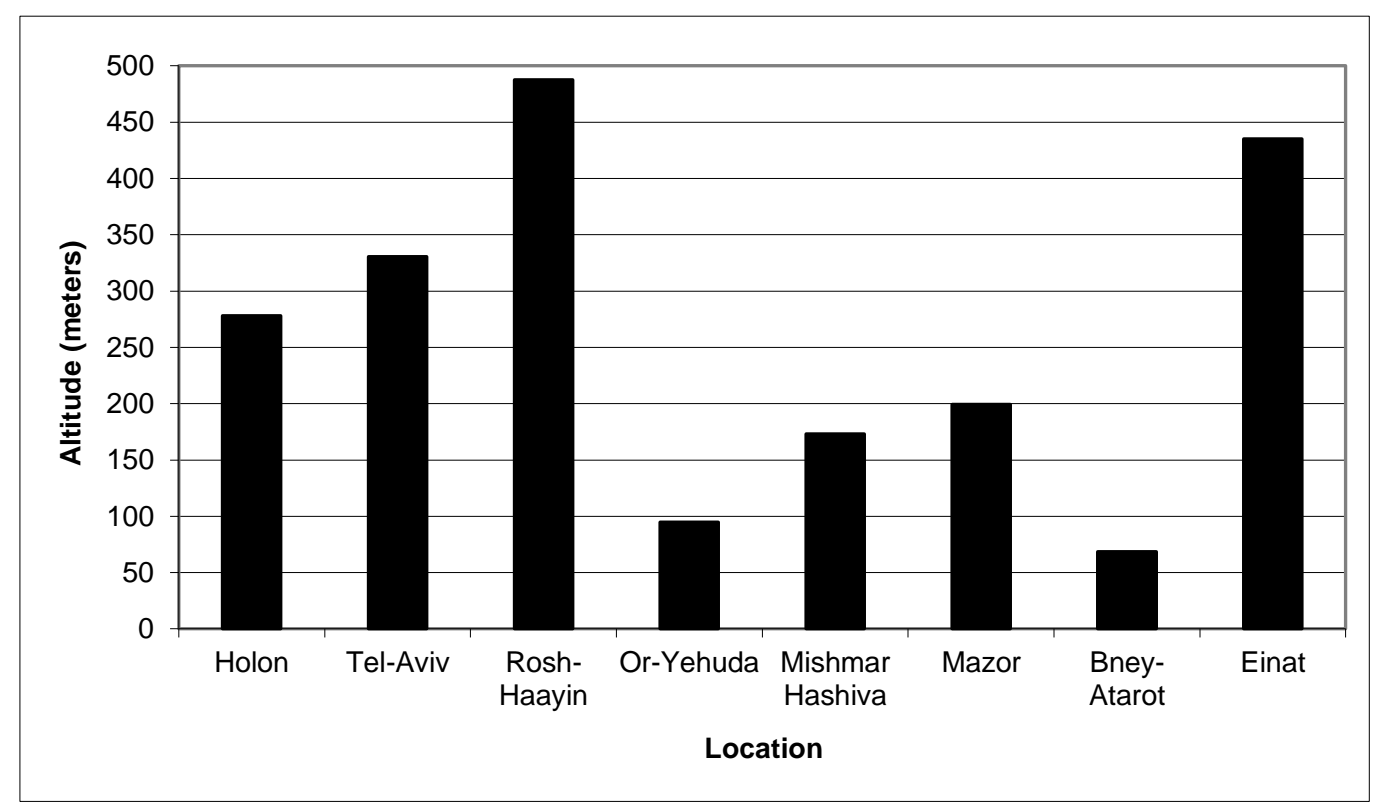

Fig. 6 Airplane altitudes in several locations near Ben-Gurion Airport

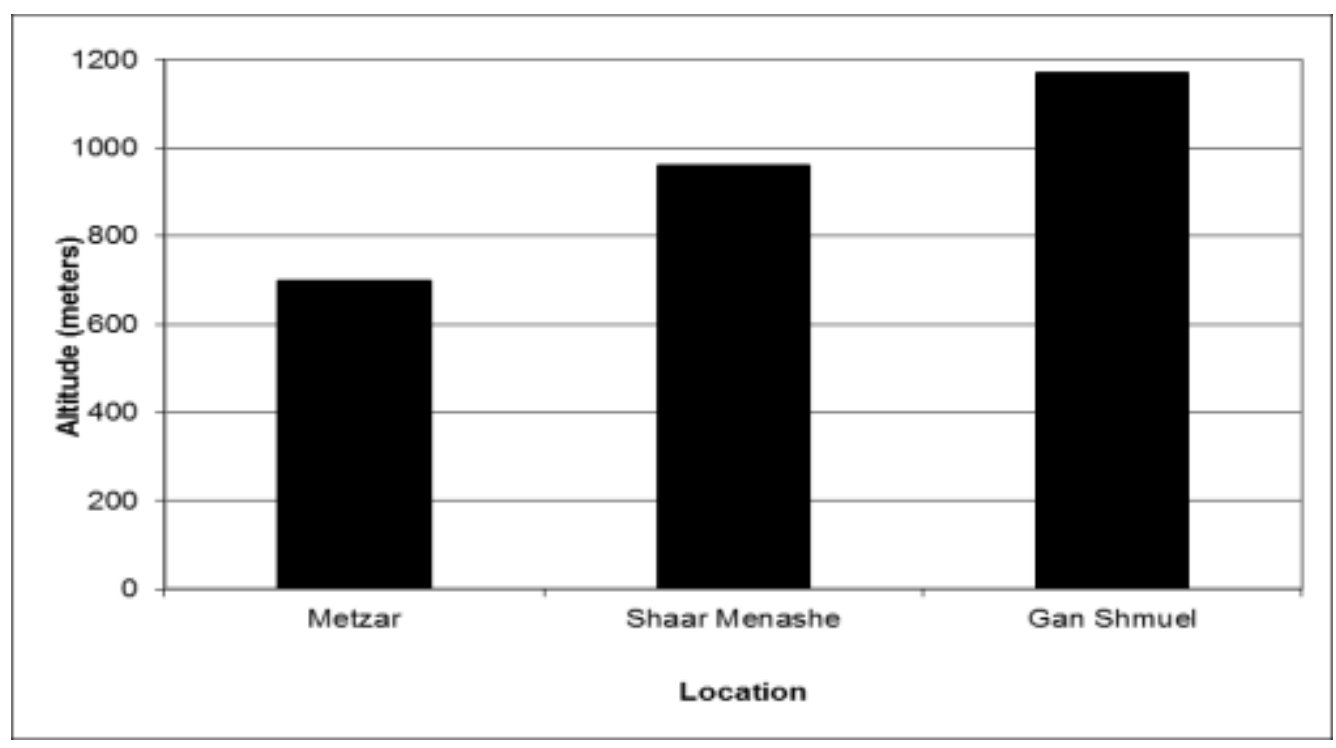

Fig. 7. Airplane altitudes in several locations near Dothan Airport 
For that reason, when our concern is the airplane noise, the main issue will be the airplane altitude. If the altitude is doubled, the noise level will reduced by $6.0206 \mathrm{~dB}$. We calculated the noise levels for three common airplanes - Airbus A380 (introduced at 2007), Boeing 747-400 (introduced at 1989) and Boeing 707 (introduced at 1958). All of these airplanes are currently in use in Ben-Gurion Airport. It should be noted that typically newer airplanes produce less noise [21]. The calculation of noise levels of these airplanes in several cities in the vicinity of Ben-Gurion Airport are detailed in Fig. 8.

The noise levels described in Fig. 8 are intolerable. Ben-Gurion International Airport is located in the vicinity of very populated areas. The noise level is excessively high and the people living in the vicinity of Ben-Gurion Airport justifiably complain about this intolerable noise $[22,23]$.

Unlike Ben-Gurion Airport, The noise nuisance near the possible Dothan Valley Airport will be much more reasonable. The noise will affect much fewer people and will be much lower. The calculation of noise levels of the same airplanes in the locations in the vicinity of possible Dothan Valley Airport are detailed in Fig. 9.

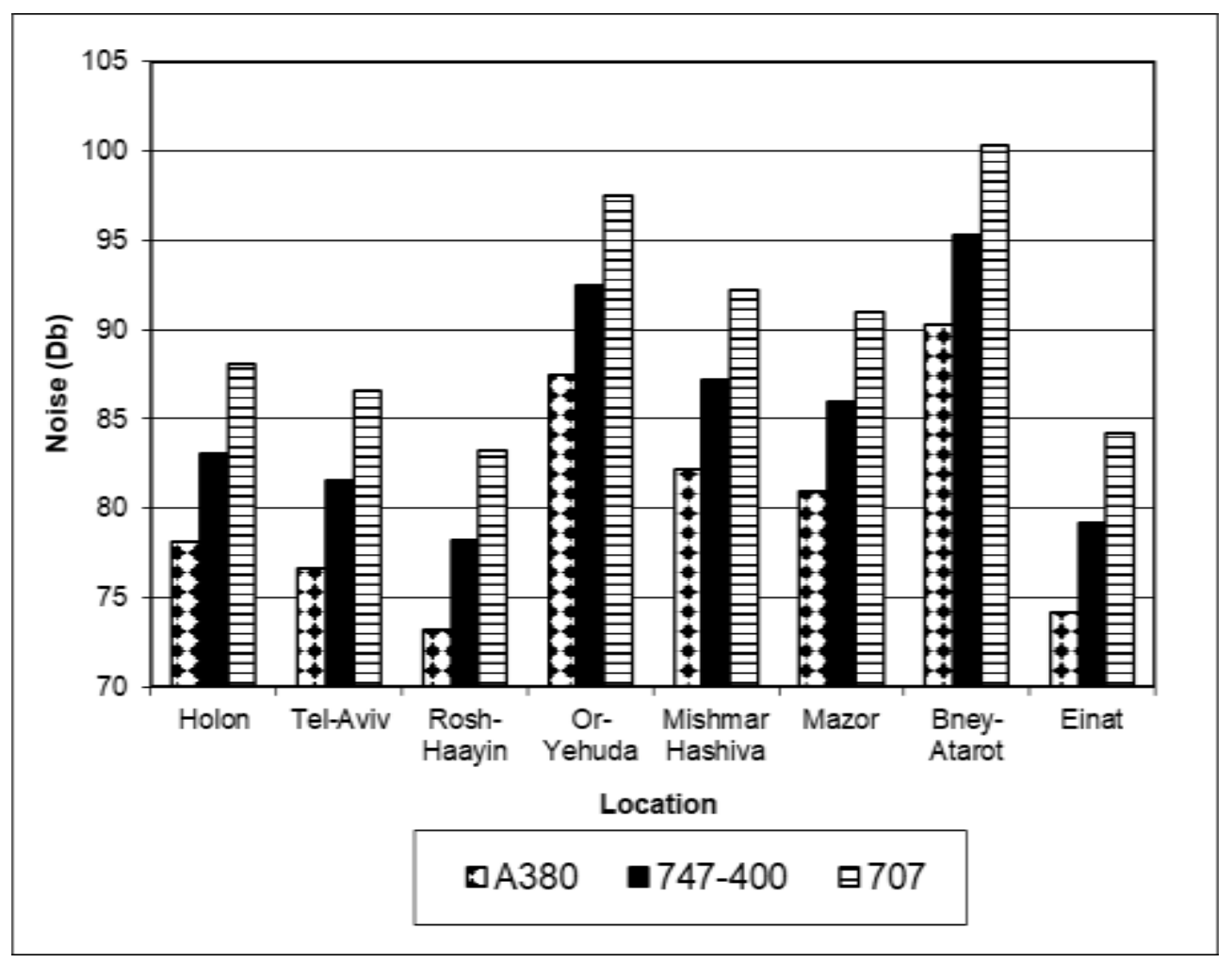

Fig. 8 Noise level in several locations near Ben-Gurion Airport 


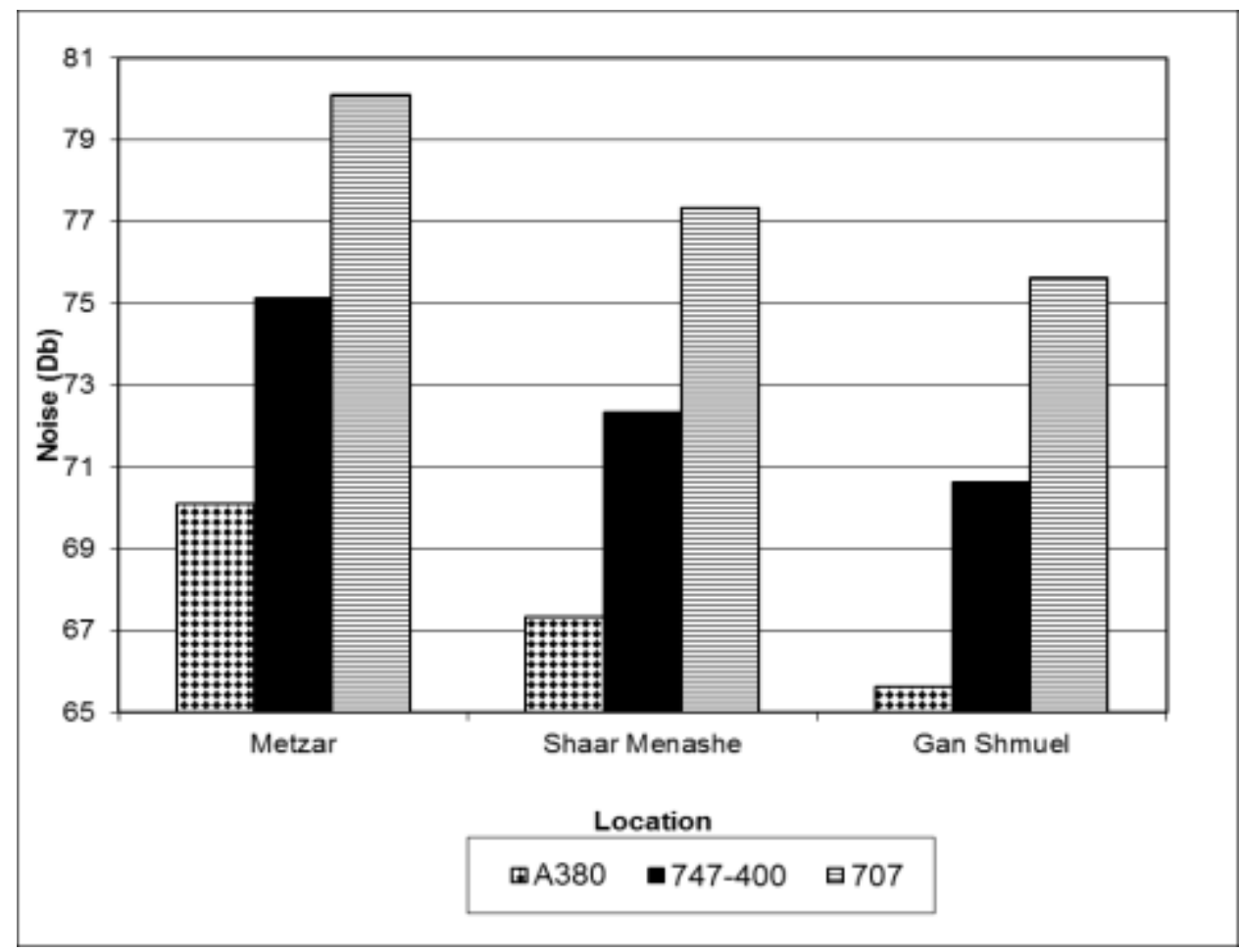

Fig. 9. Noise level in several locations near Ben-Gurion Airport

\section{CONCLUSIONS}

Ben-Gurion airport is overloaded and in addition it is located in the vicinity of populated areas and therefore it produces an exceedingly noise nuisance in its surrounding area. Rerouting of flights at nights is widespread [24]; however BenGurion airport is active until very late in the night and in some nights it is even active all over the nights. Causing noises of more than $70 \mathrm{~dB}$ in nights is clearly intolerable and unacceptable. The best way out of the overload and the noise nuisance must be shifting some of the air traffic to a new airport in Dothan Valley.

\section{REFERENCES}

[1] C. Greenman and J. Gorjidooz, "Economic Impact of World Bank Aviation Investment in Pacific Island Countries", Journal of Economics and Public Finance, (JEPF), Vol. 3, No. 3, pp. 343-357, (2017).

[2] IATA, Worldwide Slot Management Standards, (2017). Available online at: https://www.iata.org/policy/slots/Documents/wsg-8-english.pdf

[3] M. Raz-Chaimovich, "Air Fares to Western Europe Have Fallen 15\% Since the Open Skies Agreement with the EU was Signed", Globes, (2017), Available on at: https://en.globes.co.il/en/article-open-skiesbring-lower-prices-1001173680

[4] M. Raz-Chaimovich, "Record 3.6m tourists visit Israel in 2017", Globes, (2017), Available on at: https://en.globes.co.il/en/article-record-36m-tourists-visit-israel-in-2017-1001217309

[5] I. Shafran et al., Israel Planning Administration, (2017), Available online at: http://www.noairport.org.il/wp-content/uploads/2018/03/\%D7\%93\%D7\%95\%D7\%97-

\%D7\%A9\%D7\%A4\%D7\%A8\%D7\%9F-\%D7\%93\%D7\%95\%D7\%97$\% \mathrm{D} 7 \% 9 \mathrm{E} \% \mathrm{D} 7 \% \mathrm{~A} 0 \% \mathrm{D} 7 \% 94 \% \mathrm{D} 7 \% 9 \mathrm{C}-$ \%D7\%94\%D7\%AA\%D7\%9B\%D7\%A0\%D7\%95\%D7\%9F.pdf

[6] O. Hakan, and N. Yildirim, "New Model for the Optimization of Runway Orientation." Journal of Transportation Engineering, Vol. 140, no. 3, paper no. 04013020, (2013).

[7] I. M. Mills, B. N. Taylor and A. J. Thor, "Definitions of the units radian, neper, bel and decibel." Metrologia Vol. 38, no. 4, p. 353, (2001).

[8] L. L. Beranek and T. Mellow, "Acoustics: Sound Fields and Transducers", Academic Press, (2012).

[9] C. J. Plack, "The sense of hearing", Second Edition, Psychology Press, Taylor and Francis Group, NewYork, (2014). 
[10] R. Tam, "Application and Sensitivity of Airport Noise-Damage Costs", Transportation Research Record: Journal of the Transportation Research Board, SAGE journals, Vol. 2362, No. 1, pp. 35-41, (2013).

[11] M. Rashid, K. G. Jillani, S. K. Alam, and S. Abdul Jalal, "Effect of 90 decibel noise of 4000 hertz on blood pressure in young adults." Journal of Ayub Medical College, Abbottabad: JAMC, Vol. 16, No. 2, pp. 30-33, (2003).

[12] Israel Airports Authority, Frequently asked question, (2019), available online at: http://www.iaa.gov.il/en-US/natureandenvironment/Pages/FAQ.aspx

[13] Israel Ministry of Transport - The Civil Aviation Authority of Israel (CAAI), http://caa.gov.il/index.php?option=com_docman\&task=doc_download\&iotype $=$ w\&gid=4240\&Itemid= \&lang_ovrrde=ENG, (2014).

[14] Y. Wiseman and Y. Giat, Multi-modal passenger security in Israel, Multimodal Security in Passenger and Freight Transportation: Frameworks and Policy Applications, Edward Elgar Publishing Limited, Chapter 16, pp. 246-260, (2016).

[15] P. Weisberg, and Y. Wiseman,"Efficient Memory Control for Avionics and Embedded Systems", International Journal of Embedded Systems, Vol. 5, no. 4, pp. 225-238, (2013).

[16] Y. Wiseman and A. Barkai, "Smaller Flight Data Recorders", Journal of Aviation Technology and Engineering, Vol. 2, no. 2, pp. 45-55, (2013).

[17] R. Price, "Electronic flight instrument displays", US Patent Application no. 10/420602, Publication no. US20030193411 A1, (2003).

[18] V. G. Hendrikus and R. A. A. Wijnen, "Optimization of noise abatement departure trajectories." Journal of Aircraft (AIAA), Vol. 38, no. 4, pp. 620-627, (2001).

[19] F. Netjasov, "Contemporary measures for noise reduction in airport surroundings", Applied Acoustics Journal, Published by Elsevier, Vol. 73, pp. 1076-1085, (2012).

[20] J. T. M. Smith, "Aircraft Noise", 2004 edition, Cambridge University Press, UK, (2004).

[21] U. Michel, B. Barsikow, J. Helbig, M. Hellmig, and M. Schüttpelz, "Flyover noise measurements on landing aircraft with a microphone array", American Institute of Aeronautics and Astronautics (AIAA), Paper no. 2336, (1998).

[22] Y. Wiseman Y., "Noise Abatement Solutions for Ben-Gurion International Airport", International Journal of U- \& E-Service, Science \& Technology, Vol. 7(6), pp. 265-272, (2014).

[23] Y. Wiseman, "Noise Abatement at Ben-Gurion International Airport", Advanced Science and Technology Letters, Vol. 67, pp. 84-87, (2014).

[24] T. A. Feo and J. F. Bard, "Flight scheduling and maintenance base planning", Management Science, Vol. 35, No. 12, pp. 1415-1432, (1989). 